Supporting Information

\title{
Wicking Enhanced Critical Heat Flux for Highly Wetting Fluids on Structured Surfaces
}

Md Mahamudur Rahman ${ }^{1}$, Shakerur Ridwan ${ }^{2}$, Donald Fehlinger ${ }^{2}$, and Matthew McCarthy ${ }^{2 *}$

${ }^{1}$ Department of Mechanical Engineering, University of Texas El Paso, El Paso, TX, 79968, USA

${ }^{2}$ Department of Mechanical Engineering and Mechanics, Drexel University, Philadelphia, PA, 19104, USA

*Corresponding Author: mm3584@drexel.edu

Number of pages: 3

Number of figures: 2

Number of schemes: 0

Number of tables: 0

$\underline{\text { Video \# } 1}$

Water Wicking 100x reduced speed

$\underline{\text { Video \# } 2}$

FC 72 Wicking 100x reduced speed 


\section{Wicking of FC 72 on Structured Surfaces}

Figure S1a shows the wicked volume as a function of time and Fig. S1b presents the wetted area as a function of time for all the structured surfaces fabricated for this work. Here time $\mathrm{t}=0 \mathrm{~ms}$ is the time when the liquid level inside the capillary tube starts changing. The initial wicked volumetric flowrate is taken as the linear ingredient at time $\mathrm{t}=0 \mathrm{~ms}$ in the time $\mathrm{t}=0 \mathrm{~ms}$ to $\mathrm{t}=15 \mathrm{~ms}$ region. And the wetted area is taken as the average wetted area in the same time frame.
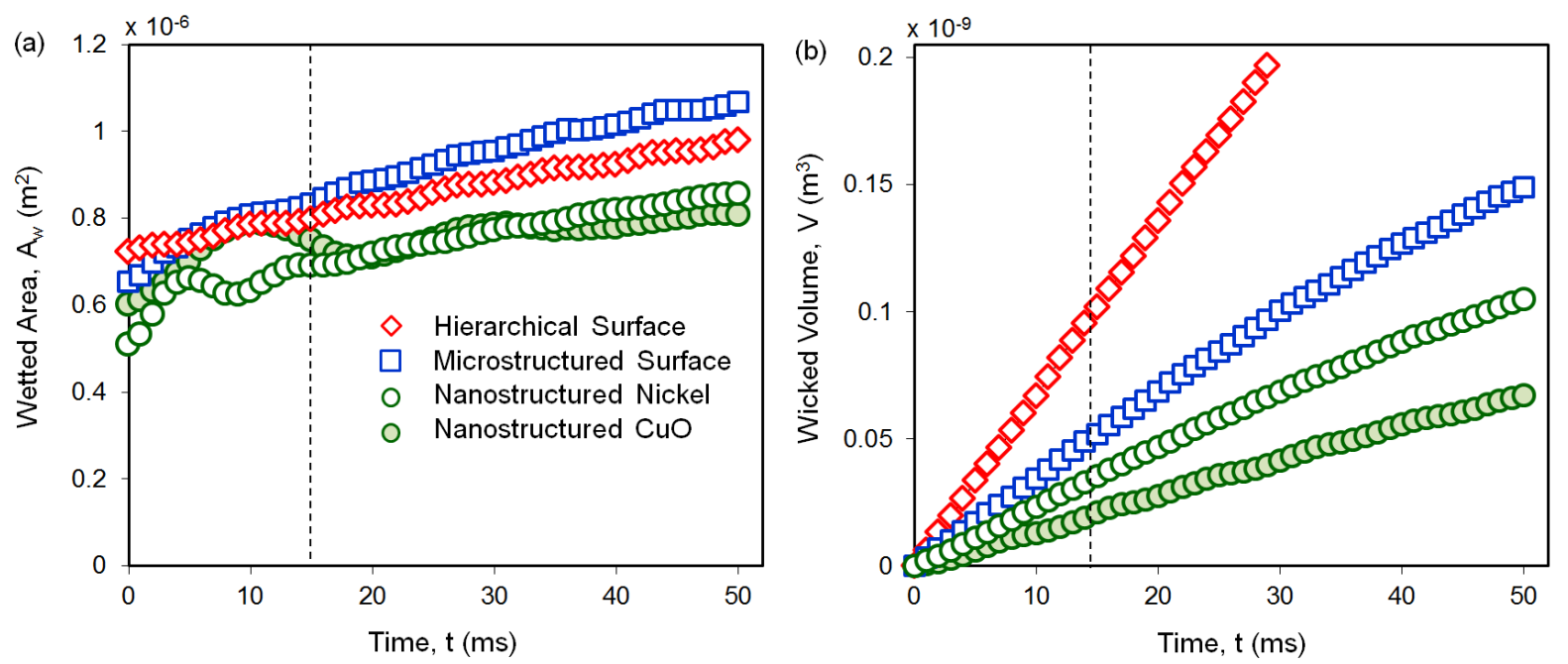

Figure S1: Capillary wicking results for the micro, nano and hierarchical structured surfaces using FC 72. (a) Wicked volume as a function of time and (b) Wetted area as a function of time.

\section{Boiling of FC 72 on Bare Surfaces}

Figure S2 shows the comparative pool FC 72 boiling heat flux as a function of wall superheat curves for bare copper (Fig. S2a) and bare silicon (Fig. S2b) surfaces with the boiling curves in the literature. ${ }^{1,2,3}$ Although boiling is a complex phenomenon which generates different boiling curves and varies among researchers' results depending on surface finish, and experimental methods, and nucleation, it can be seen that the reference boiling results presented here are in good agreement in terms of both $\mathrm{CHF}$ and $\mathrm{HTC}$ at CHF. 

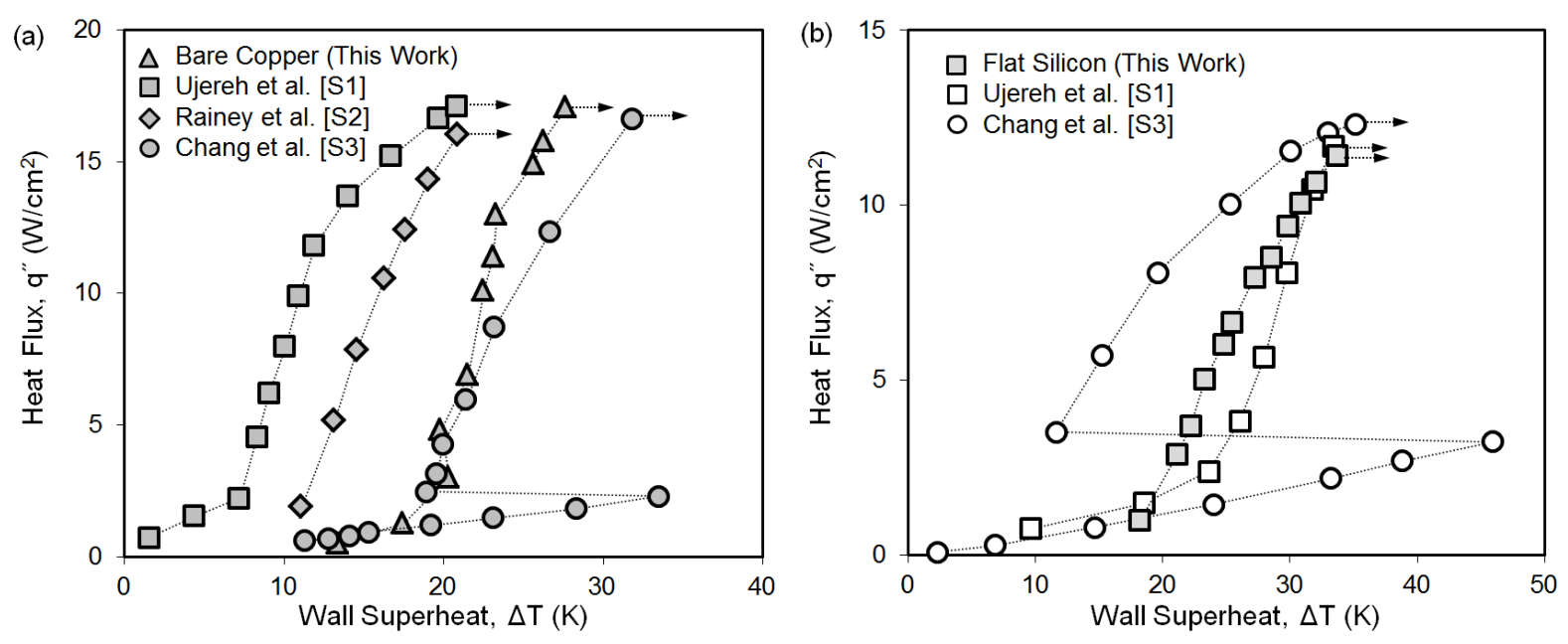

Figure S2: Pool boiling heat flux as a function of time for (a) bare copper and (b) bare silicon surfaces compared with literature. ${ }^{\mathrm{S} 1, \mathrm{~S} 2, \mathrm{~S} 3}$

\section{References}

1. Ujereh, S.; Fisher, T.; Mudawar, I., Effects of carbon nanotube arrays on nucleate pool boiling. International Journal of Heat and Mass Transfer 2007, 50 (19-20), 4023-4038.

2. Rainey, K. N.; You, S. M., Effects of heater size and orientation on pool boiling heat transfer from microporous coated surfaces. International Journal of Heat and Mass Transfer 2001, 44 (14), 2589-2599.

3. Chang, J. Y.; You, S. M., Heater Orientation Effects on Pool Boiling of Micro-PorousEnhanced Surfaces in Saturated FC-72. Journal of Heat Transfer 1996, 118 (4), 937-943. 